\title{
Pengaruh warna led berkedip yang berbeda terhadap hasil tangkapan pancing cumi-cumi di perairan Tahuna Kelurahan Santiago Kabupaten Kepulauan Sangihe
}

\author{
Effects of colored blinking led on squid catch rates in Tahuna waters Kelurahan Santiago \\ Kabupaten Kepulauan Sangihe
}

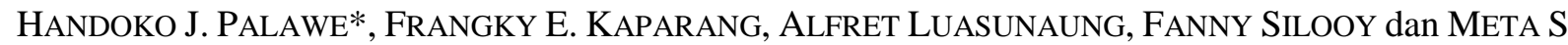 \\ SOMPIE
}

Program Studi Pemanfaatan Sumberdaya Perikanan, Fakultas Perikanan Dan Ilmu Kelautan, Universitas Sam Ratulangi, Manado

\begin{abstract}
The low catch for fishing squid with traditional method has been an issue for decades in Santiago Village, Sangihe Island Regency, thus urgently requiring the application of a new method. One of the best-modified methods for attracting fish and increasing catch is the use of artificial lights. The aim of this study was to examine the effect of illumination with white, red, green and blue light emitting diode (LED) on the squid catch rates and the number of squid catch. The four different light combinations were designed and analyzed using Latin Square Design (LSD). The results showed minor effects of green and red while the highest effect of white and blue colored LED on squid catch rates.
\end{abstract}

Keywords: LED, Sangihe, squid fishing rod, illumination

\begin{abstract}
ABSTRAK
Rendahnya tangkapan cumi dengan menggunakan alat tangkap tradisional telah menjadi masalah selama puluhan tahun di Kelurahan Santiago Kepulauan sangihe sehingga sangat menuntut aplikasi metode penangkapan baru. Salah satu metode modifikasi terbaik untuk menarik ikan dan meningkatkan hasil tangkapan ialah dengan menggunakan cahaya buatan. Tujuan dari penelitian ini adalah untuk mempelajari pengaruh iluminasi warna cahaya lampu light emitting diode (LED) terhadap jumlah dan rerata tangkapan cumi-cumi. Kombinasi empat cahaya berbeda dirancang dan dianalisa menggunakan Rancangan Bujur Sangkar Latin (RBSL). Hasil penelitian menunjukkan pengaruh tak nyata dari iluminasi warna hijau dan merah tetapi pengaruh sangat nyata (tertinggi) dari iluminasi warna putih dan biru terhadap hasil tangkapan cumi-cumi.
\end{abstract}

Kata-kata kunci: LED, Sangihe, pancing cumi-cumi, iluminasi

\section{PENDAHULUAN}

Kabupaten Kepulauan Sangihe secara astronomis terletak di antara $2^{0} 4{ }^{\prime} 13^{\prime \prime}$ - 4044'22',

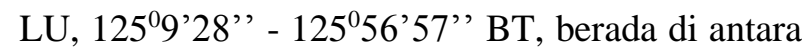
Pulau Sulawesi dan Pulau Mindanao Republik Philipina, sehingga dapat dikategorikan sebagai daerah perbatasan. Kabupaten Kepulauan Sangihe memiliki garis pantai mencapai $\pm 297 \mathrm{~km}$, dimana pengembangannya lebih dominan pada pemanfaatan sumberdaya perikanan dan kelautan. Perikanan merupakan salah satu sektor potensi unggulan daerah yang selama ini menjadi penggerak utama pertumbuhan ekonomi Kabupaten Kepulauan Sangihe. Produksi ikan berasal dari perikanan tangkap (LKPJ Kabupaten Kepulauan Sangihe, 2017). Perairan Kabupaten Kepulauan Sangihe masuk ke dalam WPP 716. Potensi perikanan tangkap di Kabupaten Kepulauan Sangihe adalah sekitar $67,752,20$ ton per tahun.

\footnotetext{
*Penulis untuk penyuratan; email: handokopalawe16@gmail.com
} 
Dari potensi tersebut yang baru termanfaatkan baru $15,01 \%$ atau berkisar $10.137,16$ ton (BPS Sangihe, 2014).

Berdasarkan DKP RI-JICA (2009) bahwa salah satu sumberdaya laut dalam bidang perikanan tangkap yang dikenal ekonomis penting yang mendominasi hasil tangkapan nelayan di perairan Indonesia dari jenis moluska, yaitu cumi-cumi. Umumnya masyarakat nelayan di Kelurahan Santiago Kabupaten Kepulauan Sangihe menggunakan pancing cumi-cumi, karena proses pembuatan alat tangkap sampai pada proses pengoperasian alat tangkap ini tidak terlalu banyak biaya. Alat tangkap pancing cumi-cumi di Kabupaten Kepulauan Sangihe, khususnya di Kelurahan Santiago umumnya masih bersifat tradisional tapi nelayan memodifikasi alat tangkap ini dengan tambahan alat bantu penangkapan yang modern seperti lampu LED untuk memikat cumicumi mendekati pancing, nelayan biasanya menggunakan lampu LED dengan warna yang berbeda.

Alat tangkap Pancing cumi-cumi sudah lama dikenal dan dioperasikan lampu LED yang di pasang langsung pada tali utama pancing dengan warna cahaya yang beragam, nelayan di Kelurahan Santiago menggunakan warna lampu tersebut berdasarkan keinginan mereka tanpa memperhatikan pengaruhnya terhadap hasil tangkapan. Permasalahannya adalah belum diketahui pengaruh warna cahaya dari lampu LED berkedip yang cocok dan sangat mempengaruhi hasil tangkapan cumi-cumit, oleh karena itu dipandang perlu adanya dilakukan penelitian tentang pengaruh beberapa warna cahaya lampu LED berkedip yang memberikan hasil tangkapan cumi-cumi yang maksimum dari warna lampu LED berkedip lain. Tujuan Penelitian ini adalah mempelajari pengaruh warna cahaya lampu LED berkedip dengan 4 kombinasi warna, yaitu : BiruHijau (BH), Merah-Biru (M-B), Merah-Hijau (MH), Putih-Biru (BH) dan mempelajari keberhasilan warna lampu LED berkedip terhadap jumlah hasil tangkapan cumi-cumi.

\section{METODE PENELITIAN}

Penelitian ini dilaksanakan di perairan pantai Kelurahan Santiago, Kabupaten Kepulauan Sangihe, Provinsi Sulawesi Utara. Waktu pelaksanaan penelitian berlangsung selama empat bulan yaitu dari bulan Agustus - November 2018.
Alat dan bahan yang digunakan dalam penelitian ini yaiut Pancing cumi-cumi (4 unit), Kamera, Lampu LED berkedip Perahu tipe pelang (4 unit), Timbangan, Meteran, GPS. Sedangkan bahan yang digunakan yaitu Bahan bakar mesin (bensin) dan umpan cumi berupa daging ikan selar. Rangkaian alat tangkap pancing cumi dapat dilihat pada gambar 1 .

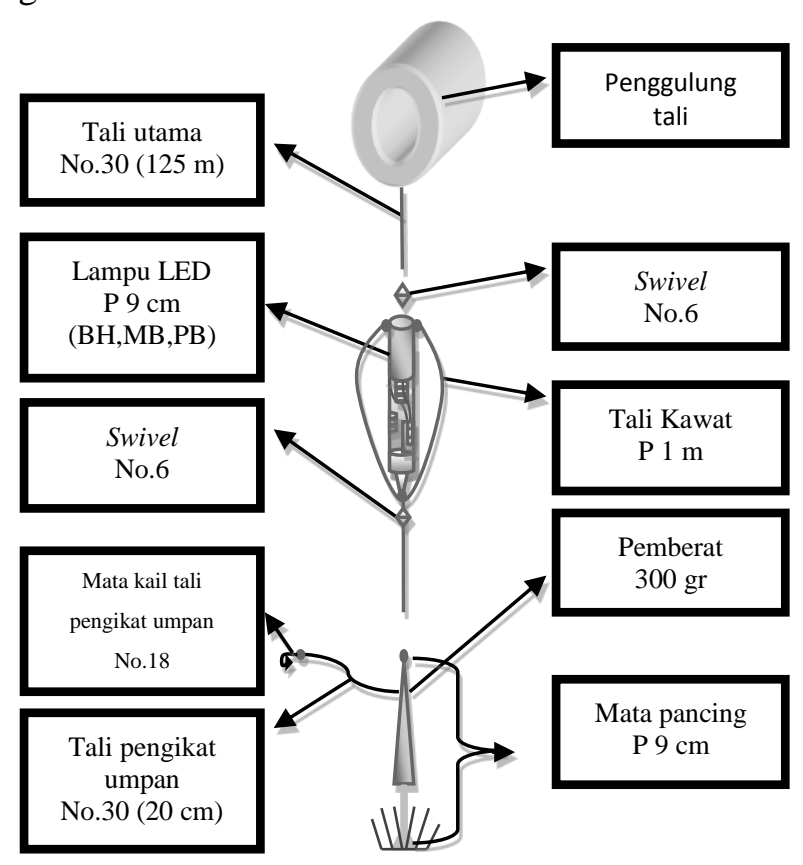

Gambar 1. Rangkaian Alat Tangkap Pancing Cumi

\section{Teknik Pengumpulan Data}

Teknik pengumpulan data dikumpulkan melalui pengamatan langsung terhadap objek penelitian. Data primer mencakup pengamatan terhadap objek penelitian berupa pengoperasian alat tangkap, alat bantu lampu LED berkedip dalam air, fishing ground, serta jumlah tangkapan selama 8 trip. Sedangkan data sekunder yang diperoleh berdasarkan studi kepustakaan tentang tingkah laku cumi-cumi, pancing cumi-cumi, lampu LED, atau apa saja yang terkait di dalam penelitian.

Pengoperasian alat tangkap pancing cumicumi dilakukan pada malam hari pada pukul 19.00 - 23.00 wita dengan menggunakan 4 perahu, dimana tiap-tiap perahu dikenai satu perlakuan, yaitu Lampu Led berkedip dengan warna yang berbeda. Sebelum dilakukam pengoperasian alat tangkap, terlebih dahulu 
disiapkan peralatan dan penentuan titik lokasi daerah penangkapan menggunakan GPS.

Sebelum menuju ke daerah penangkapan (fishing ground), nelayan selalu mempersiapkan segala hal, diantaranya : mengisi bahan bakar, menyiapkan peralatan pancing cumi, umpan, bekal makanan. Setelah semua selesai, maka nelayan siap berangkat ke daerah penangkapan (fishing ground). Waktu dan jarak yang ditempuh dari lokasi berangkat sampai ke daerah penangkapan ikan (fishing ground) 15 menit dengan kecepatan Perahu 6 knot. Jarak yang di tempuh sekitar 1.5 mil laut

\section{Analisis Data}

Penelitian ini didasarkan pada desain Rancangan Bujur Sangkar Latin (RBSL) yaitu mampu mengendalikan komponen keragaman unit-unit percobaan lebih dari satu komponen keragaman (Bambang, $d k k$, 2011). Perlakuan dalam penelitian ini terdiri dari:

I. Perlakuan A =lampu LED berkedip berwarna biru-hijau;

II. Perlakuan B =lampu LED berkedip berwarna merah-biru;

III. Perlakuan $\mathrm{C}=$ lampu LED berkedip berwarna merah-hijau;

IV. Perlakuan $\mathrm{D}=$ lampu LED berkedip berwarna putih-biru.

Model Linier untuk rancangan bujur sangkar latin adalah :

$\mathbf{Y}_{\mathrm{ij}(\mathrm{t})}=\boldsymbol{\mu}+\boldsymbol{\beta}_{\mathrm{i}}+\mathbf{K}_{\mathrm{i}}+\mathbf{P}_{(\mathrm{t})}+\varepsilon_{\mathrm{ij}}$

Dimana $: \mathrm{i}=1,2 \ldots \mathrm{n} ; \mathrm{j}=1,2, \ldots \mathrm{n}$; dan $\mathrm{t}=1,2$, ...n

$\mathrm{Y}_{\mathrm{ij}(\mathrm{t})}=$ nilai pengamatan pada baris ke-i, kolom

$\mathrm{ke}-\mathrm{j}$ yang mendapat perlakuan ke-t.

$\mu=$ nilai rata-rata umum

$\beta_{\mathrm{i}}=$ pengaruh baris ke- $\mathrm{i}$

$\mathrm{K}_{\mathrm{i}}=$ pengaruh kolom ke- $\mathrm{j}$

$\mathrm{P}_{(\mathrm{t})}=$ pengaruh perlakuan ke-t

$\varepsilon_{\mathrm{ij}(\mathrm{t})}=$ pengaruh galat pada baris ke-i, kolom ke-j yang memperoleh perlakuan ke-t

Setelah itu dilanjutkan dengan Koefisien Keragaman, untuk menunjukkan derajat kejituan (accuracy) serta keandalan kesimpulan. Koefisien Keragaman (KK) dirumuskan seperti berikut:

$\mathrm{KK}=\{\{\sqrt{ }(\mathrm{KTG})\} / \bar{y}\} \times 100 \%$

Dimana : $\bar{y}=($ rerata umum $) \quad=\mathrm{T} / \mathrm{r}^{2}$

$$
=\sum^{\mathrm{ij}}{ }_{\mathrm{Yij}} / \mathrm{r}^{2}
$$

Kemudian dilanjutkan dengan Uji Beda Nyata Jujur (BNJ), Untuk mengetahui perlakuanperlakuan yang berbeda antara satu dengan lainnya.

$B N J=$ tukey $\frac{1}{\sqrt{2}} \sqrt{\mathbf{K T G}\left(\frac{1}{\mathbf{n}_{\mathbf{i}}}+\frac{1}{\mathbf{n}_{\mathbf{j}}}\right)}$

Keterangan : KTG $=$ Kuadtar Tengah Galat

$\mathrm{n}_{\mathrm{j}}=$ Jumlah ulangan

$\mathrm{n}_{\mathrm{i}}=$ Jumlah Perlakuan

\section{HASIL DAN PEMBAHASAN}

\section{Hasil Tangkapan}

Jumlah total hasil tangkapan yang dilakukan selama penelitian,yaitu 183 ekor. Hasil tangkapan Pada perlakuan A (Biru-Hijau) 25 ekor, perlakuan B (Merah-Biru) 55 ekor, perlakuan C (Merah-Hijau) 17 ekor, dan Perlakuan D (Putih-Biru) sebanyak 86 ekor. Data hasil tangkapan tersebut dapat dilihat pada tabel 1 .

Tabel 1. Data Hasil Tangkapan Cumi-cumi (ekor) menurut perlakuan

\begin{tabular}{llll}
\hline \multicolumn{4}{c}{ Hasil Perlakuan } \\
$\mathrm{A}_{(\text {B.H) }}$ & $\mathrm{B}_{(\text {M.B) }}$ & $\mathrm{C}_{(\text {M.H })}$ & $\mathrm{D}_{(\text {P.B })}$ \\
\hline 7 & 3 & 14 & 22 \\
8 & 6 & 17 & 21 \\
4 & 4 & 12 & 23 \\
6 & 4 & 12 & 20 \\
25 & 17 & 55 & 86 \\
\hline
\end{tabular}

Secara deskriptif, rataan jumlah hasil tangkapan cumi-cumi pada setiap perlakuan menunjukan bahwa hasil tangkapan tertinggi terdapat pada perlakuan D, yatu lampu Led berkedip berwarna (putih-biru) dan terendah terdapat pada perlakuan B),sedangkan kontrol (Tidak menggunakan LED) tidak mendapatkan hasil tangkapan apapun. Data tersebut dapat dilihat pada gambar 2 .

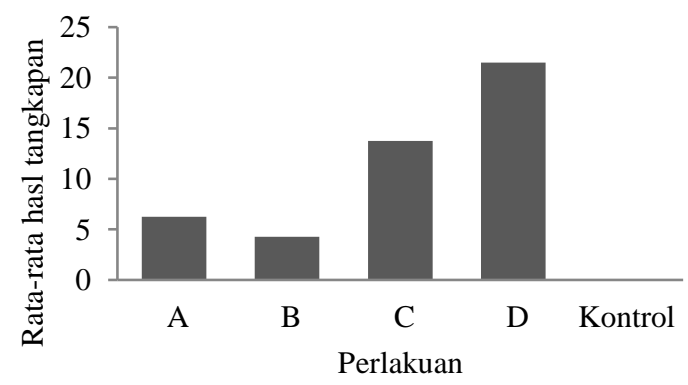

Gambar 2. Histogram Hasil Tangkapan Cumi-cumi 


\section{Hasil Analisis Data}

Analisis data penelitian di mulai dari tabulasi data hasil tangkapan kedalam tabel Rancangan Bujur Sangkar Latin. Data tersebut dapat dilihat pada tabel .

Kemudian data tersebut dianalisis menggunakan analisis Sidik ragam pada Rancangan Bujur Sangkar Latin.

Data hasil analisis Sidik Ragam dapat dilihat pada tabel 2.
Tabel 2. Tabulasi data hasil tangkapan cumi-cumi (ekor) dalam RBSL

\begin{tabular}{lccccc}
\hline \multicolumn{1}{c}{ Tanggal } & \multicolumn{3}{c}{ Hasil Perlakuan } & Jumlah \\
\hline 27 \& 31 okt 2018 & 7 & 3 & 14 & 22 & 46 \\
28 okt \& 1 nov & 21 & 8 & 6 & 17 & 52 \\
29 okt \& 2 nov & 12 & 23 & 4 & 4 & 43 \\
30 okt \& 3 nov & 4 & 12 & 20 & 6 & 42 \\
Jumlah & 44 & 46 & 44 & 49 & 183 \\
\hline
\end{tabular}

Tabel 3. Tabel Analisis Sidik Ragam

\begin{tabular}{llllllll}
\hline \multicolumn{1}{c}{$\begin{array}{c}\text { Sumber } \\
\text { Keragaman }\end{array}$} & $\mathrm{db}$ & \multicolumn{1}{c}{$\mathrm{JK}$} & $\mathrm{KT}$ & F hitung & signifikasi & \multicolumn{2}{c}{ F tabel } \\
\hline Baris & 3 & 15,188 & 5,063 & 3,423 & tn & 3,49 & 5,95 \\
Kolom & 3 & 11,188 & 3,729 & 2,521 & tn & \\
Perlakuan & 3 & 740,688 & 249,896 & 166,915 & $* *$ & & \\
Galat & 6 & 8,875 & 1,479 & & & \\
Total & 15 & 775,938 & & & & \\
\hline
\end{tabular}

Keterangan :

tn $=$ Tidak Nyata

$* *=$ Berbeda nyata atau sangat berpengaruh

Hasil analisis menunjukan Fhitung perlakuan lebih besar dari Ftabel 5\% dan 1\%, maka diambil kesimpulan sangat berbeda nyata atau sangat berpengaruh sehingga hipotesis $\mathrm{H} 1$ diterima atau perlakuan berpengaruh terhadap respons yang diamati. Data hasil penelitian ini sangat baik karena tidak adanya pengaruh kolom maupun baris.

Pengujian kemudian dilanjutkan dengan Uji Beda Nyata Jujur (BNJ) dan didapatkan hasil seperti pada tabel 3 .

Tabel 4. Hasil Uji BNJ

\begin{tabular}{lcc}
\hline \multicolumn{1}{c}{ perlakuan } & rata-rata & signifikasi \\
\hline A (Biru-Hijau) & 6,25 & $\mathrm{AB}$ \\
B (Merah-Biru) & 13,75 & $\mathrm{ABC}$ \\
C (Merah-Hijau) & 4,25 & $\mathrm{BC}$ \\
D (Putih-Biru) & 21,5 & $\mathrm{D}$ \\
BNJ 5\% & & 4,90 \\
\hline
\end{tabular}

Berdasarkan uji BNJ tersebut, maka didapatkan hasil, bahwa perlakuan A sama dengan perlakuan B, perlakuan B sama dengan perlakuan A dan C. Perlakuan C sama dengan perlakuan B, Perlakuan D berbeda dengan Perlakuan A/B dan C, sedangkan kontrol (Tidak menggunakan LED) tidak mendapatkan hasil tangkapan apapun.

\section{Pembahasan}

Berdasarkan hasil Analisis Sidik Ragam dari Rancangan Bujur Sangkar Latin,diperoleh hasil F hitung perlakuan lebih besar dari sedangkan $\mathrm{F}$ hitung dari Baris dan kolom lebih kecil dari Ftabel $5 \%$ dan $1 \%$. Hal ini menunjukan bahwa penggunaan lampu LED berkedip dengan warna yang berbeda pada pancing cumi-cumi sangat berpengaruh terhadap hasil tangkapan cumi-cumi.

Perbedaan jumlah hasil tangkapan cumi-cumi ini terindikasi disebabkan oleh respon cumi-cumi terhadap warna lampu yang disukai. (Maryam, $d k k$, 2012). Adanya pengaruh warna lampu LED terhadap hasil tangkapan cumi-cumi antara keempat perlakuan yang dilakukan dalam penelitian ini, diduga erat kaitanya dengan kondisi perairan pada saat itu, dimana perlakuan berwarna putih-biru memiliki jumlah hasil tangkapan dari perlakuan lainnya. Hal ini disebabkan kondisi cuaca saat proses penangkapan di lakukan. Saat perairan tidak tenang karena cuaca (angin dan bergelombang) dapat mempengaruhi hasil tangkapan (Derec, 2009), 
Penelitian ini sejalan dengan penelitian yang dilakukan oleh Mulyawan $d k k$, (2015) bahwa lampu berwarna putih memiliki hasil tangkapan yang lebih besar dari lampu berwarna lainnya, dimana hasil tangkapan cumi-cuminya sebanyak 64\% dibandingkan lampu lainnya. Adapun penelitian lainnya yang menunjang penelitian ini yaitu penelitian yang dilakukan oleh Hakgeun et.al, (2012) bahwa warna lampu yang paling disukai cumi-cumi adalah warna biru. Kemudian lampu LED berwarna putih juga memiliki nilai intensitas terbear dibandingkan hijau dan merah (Setiawan, $d k k$, 2015). Kombinasi dari kedua warna pada perlakuan D (Putih-Biru) memiliki intensitas cahaya lebih tinggi dibanding dengan kombinasi warna pada perlakuan A,B,dan C. Sehingga respon cumi-cumi lebih dominan pada warna putih-biru. Sebaliknya pada penelitian yang dilakukan oleh Gunarso, (1985) yang menyatakan bahwa lampu berwarna biru memiliki hasil tangkapan lebih rendah dibandingkan dengan lampu berwarna merah dan hijau. Hal ini dapat dijelaskan, bahwa pada saat lampu berwarna biru berada dalam air pada daerah terang, akan kurang memantulkan cahaya atau kilau cahaya yang dapat dilihat atau dideteksi oleh cumi-cumi, sehingga peluang tertangkapnya lebih sedikit dibandingkan warna lampu lainnya.

\section{KESIMPULAN}

Dari hasil penelitian dapat disimpulkan bahwa penggunaan warna lampu LED berkedip pada pancing cumi-cumi sangat berpengaruh terhadap hasil tangkapan cumi-cumi. Hasil analisis menunjukan $\mathrm{F}$ hitung perlakuan lebih besar dari $\mathrm{F}$ tabel 5\%. Maka diambil kesimpulan sangat berbeda nyata atau sangat berpengaruh sehingga hipotesis H1 diterima atau perlakuan berpengaruh terhadap respons yang diamati. Tingkat keberhasilan penangkapan dari keempat perlakuan lampu LED tersebut adalah pada perlakuan D, yaitu lampu LED berkedip yang berwarna Putih-Biru.

\section{SARAN}

Sebaiknya nelayan menggunakan lampu LED berkedip berwarna putih-biru pada pancing cumicumi, karena hasil tangkapannya lebih banyak dibandikan kombinasi warna lampu LED biruhijau,merah-biru, dan merah-hijau. Selanjutnya Perlu adanya penelitian lebih lanjut mengenai alat tangkap pancing tersebut dan warna LED lainnya yang di sesuaikan dengan musim penangkapan.

\section{DAFTAR PUSTAKA}

BPS Sangihe. 2014. Sangihe dalam angka. Badan Pusat Statistik Kabupaten Kepulauan Sangihe. http://sangihekab.bps.go.id/

Derec.M.N. 2009. Preferensi Larva Cumi-cumi Sirip Besar Terhadap Perbedaan Warna Lampu dan Tingkat Intensitas Cahaya Pada Waktu Pengamatan Yang Berbeda. Fakultas Perikanan dan Ilmu Kelautan Institut Pertanian Bogor.Bogor. 212 hal.

DKP. Departemen Kelautan dan Perikanan, 2009. Indonesian Fisheries Book 2009. Departemen Kelautan dan Perikanan dan JICA. Jakarta. 145 hal.

Gunarso. W. 1985. Studi Tentang Tingkah Laku Ikan Dalam Hubungannya dengan Metode dan Teknik Penangkapan. Jurusan Pemanfaatan Sumberdaya Perikanan. Fakultas Perikanan. Istitut Pertanian Bogor. Bogor 147 hal

Hakgeun J, Seunghwan Y, Junghoon L,Young. 2012. The retinular responses of common squid todarodes pacificus for energy efficient fishing lamp using LED. ELSEVIER Renewable Energ. 54: 10 -104.

Mulyawan, Masjamsir, dan Andriani.Y. 2015. Pengaruh Perbedaan Warna Lampu Terhadap Hasil Tangkapan Cumi-cumi (Loligo sp) Pada Bagan Apung di Perairan Pelabuhan Ratu Kabupaten Sukabumi .Jawa Barat. Vol. 6, No. 2. Hal. 116-124.

Maryam S,Katiandagho.M.E, dan Paransa J.I. 2012.Pengaruh Perbebedaan Pancing jigs Beradium dan Berlampu Terhadap Hasil Tangkapan Sotong di Perairan Pantai Sario Tumpaan Kota Manado.Jurnal Ilmu dan Teknologi Perikanan Tangkap.1(1) hal.18-21.

Pemerintah Kabupaten Kepulauan Sangihe T.A. 2017. Laporan Keterangan Pertanggungjawaban Sangihe. $140 \mathrm{Hal}$.

Setiawan,Sulistiyanti,dan Sadnowo. 2015. Analisis Pengaruh Medium Perambatan Terhadap Cahaya Lacuba (Lampu Celup Bawa Air). Universitas Bandar Lampung. Lampung.Vol.9, No1. Hal. 21-29. 